\title{
Explaining walking distance to public transport: The dominance of public transport supply
}

\author{
Rhonda Daniels ${ }^{a}$ \\ University of Sydney
}

\author{
Corinne Mulley ${ }^{b}$ \\ University of Sydney
}

\begin{abstract}
Potential influences on explaining walking distance from home to access public transport are investigated, including trip and demographic characteristics and public transport supply. In Sydney, Australia, people walk farther to the train than to the bus, the distributions of walking distances are different for each mode, and the trip and demographic characteristics of train and bus users are different. Given the decision to walk to public transport, demographic characteristics such as age, gender, income, and labor force status and trip characteristics such as trip purpose, time of day and week, fare and ticket type, and trip duration are not significant in explaining walking distance to each mode of public transport. The mode of the public transport trip is the most important determinant of walking distance, reflecting the different supply and spacing of each mode. For instance, there are many more bus stops than train stations. The differences between train and bus users suggest that accessibility initiatives for public transport might not be the same for each mode.
\end{abstract}

\section{Introduction}

Public transport plays a key role in ensuring accessibility to activities and services. There are many influences on the use of public transport, including spatial access, cost, physical accessibility, information, and attitudes, all of which contribute to people's ability and motivation to use public transport. This research focuses on spatial access because understanding influences on walking distance to public transport is a key element of establishing equitable access to public transport.

Guidelines for public transport planning usually specify access to public transport in terms of spacing between public transport stops or distance to stops. Average walking distances are typically longer to access rail than to access buses. But it is important to go beyond averages, and understand, given the current spacing and distribution of public transport, how walking distances vary by characteristics of public transport users and their trips. This has important implications for providing accessibility to the community by recognizing differences within the community. Understanding the characteristics and variability of the walking access trip is important to add to an evidence base, which has often subsumed this element of the public transport trip as part of the total trip.

From the existing literature on walking, potential influences on the characteristics and variability of walking distance as an access mode to public transport include trip purpose, demographics, built environment, local geography, and public transport supply. The research uses Sydney, Australia, as a case study to investigate the potential influences on walking distance from home to access public transport, once the decision to walk has been made.

The paper is structured as follows: Section two reviews the policy context for public transport planning, and the previous research on influences on walking distance to public transport; section three describes the data for Sydney; section four presents analysis on influences on walking distance; and section five discusses the results and draws conclusions.

\section{Policy context and literature review}

This section provides the policy context for the interest in understanding how far passengers walk to access public transport, followed by a review of possible influences on walking distances.

\subsection{Key assumptions and definitions}

Public transport is important for social inclusion, for providing access to participation in life opportunities, and for reaching activities and services such as work, education, health, shopping, and social-recreational activities (Currie et al. 2007; Lucas 2005; Lucas 2010). Accessibility planning to improve social inclusion in the UK focuses on improving access by public

${ }^{a}$ rhonda.daniels@sydney.edu.au

bcorinne.mulley@sydney.edu.au 
transport (Daniels and Mulley 2010a). Recognizing the importance of public transport, many government strategic plans publicly set goals and targets for public transport availability and use. For instance, the strategic land use and transport plans for Sydney Australia (NSW Government 2005, 2010a, 2010b, and 2010c) include a broad accessibility target of increasing the proportion of the population with access within 30 minutes by public transport to one of a set of centers, which is large enough to provide a range of activities and services (Daniels and Mulley 2010a).

In delivering public transport accessibility goals and targets, service planning makes assumptions about walking distance to access public transport. Guidelines often use onequarter mile or 400 meters, or multiples such as one-half mile or 800 meters, as key distances in network and service planning. The empirical origin of these commonly used "rules of thumb" is unclear, although Neilson and Fowler (1972) found that 70 percent of elderly bus users in a low-density Florida retirement area lived with one-eighth mile of the bus route, and bus usage at a total walking distance of one-eighth mile was three times greater than the usage at a distance of one-quarter mile.

Service planning guidelines for Sydney (NSW Ministry of Transport 2006) specify that 90 percent of households in each of the 15 metropolitan bus contract regions should be within 400 meters of a rail line and/or bus route during the day (commuter peaks, inter-peak and weekend daytime) and within 800 meters of a rail line and/or bus route at nighttime. This is measured as the straight-line distance, not road or walking distance. Similarly, Vancouver uses 400 meters (Greater Vancouver Transport Authority 2004), Helsinki uses 300 meters (HKL 2008), while Perth uses 500 meters (Public Transport Authority 2003).

Walking distance is important for at least two reasons. Walking is the primary access mode for trips from home to public transport and walking distance has a significant impact on public transport use. In Sydney, walking is the access mode for almost 90 percent of bus trips from home and for about half of train trips from home (Table 1). Ewing and Cervero (2010) reported a meta-analysis showing a public transport demand elasticity of -0.29 with respect to accessibility (measured as distance to a public transport stop), suggesting a 10 percent increase in distance to a public transport stop would decrease public transport use by approximately 3 percent.

Assumptions about distances that people will walk to access public transport or "rules of thumb" are used by transport planners to determine stop spacing, particularly for buses as these are more flexible but also by land-use planners for urban design to achieve walkable cities and plan transit-oriented developments (TODs).

\subsection{Influences on walking distance}

This section reviews the literature on influences on both walking as a mode and on walking as an access mode to public transport to identify possible explanatory variables for use in the analysis, including purpose of the trip, socio-demographic characteristics, the built and natural environments, and mode of public transport. Transport planning research has focused on mode choice, not on access to different modes, and there is a less well-established literature on how far pedestrians walk and the factors that influence their route choice (Agrawal et al. 2008). There is increasing interest in the relationship between walking and health from public-health researchers, with studies on walking as a mode by Corpuz et al. (2005), Lee and Moudon (2006), and Merom et al. (2010), and on walk time to meet physical activity requirements (Besser and Dannenberg 2005).

For walk as a mode in itself, there is some evidence that recreational walking trips, which include trips for exercise and

Table 1: Access modes from home to bus and train in Sydney on average weekday, $2008 .{ }^{1}$

\begin{tabular}{|l|r|r|}
\hline Access mode from home & To bus & To train \\
\hline Walk & $89 \%$ & $50 \%$ \\
\hline Car as driver & $2 \%$ & $17 \%$ \\
\hline Car as passenger & $9 \%$ & $17 \%$ \\
\hline Bus & - & $14 \%$ \\
\hline Other (taxi, bicycle, other) & $0 \%$ & $2 \%$ \\
\hline Total & $100 \%$ & $100 \%$ \\
\hline Total access trips per average weekday & 309,664 & 381,704 \\
\hline
\end{tabular}

Source: HTS, Bureau of Transport Statistics, data request 10/332.

${ }^{1}$ Based on pooled data from three years (2006-07, 2007-08, 2008-09), weighted to June 30, 2008, population. Sydney is Sydney Statistical Division, Illawarra Statistical Division, and Newcastle Statistical SubDivision. 
fitness, are longer than for other purposes (Corpuz et al. 2005; Iacono et al. 2008), although Iacono et al. (2008) noted that distance decay functions are similar across trip purposes. The impact of socio-demographic factors has mostly been studied in the context of being a differentiating factor in choice of travel behavior. Corpuz et al. (2005) found that in Sydney females walk more than males, older and younger age groups walk more, and people with low car ownership walk more. For access to public transport, Wibowo and Olszewski (2005) found that men were more likely to access Mass Rapid Transit (MRT) stations in Singapore by walking compared to women, although walking distance was the most significant factor in models of walking choice to access MRT stations.

The many elements of the built environment from density, diversity, and design to micro-level details, such as ambience and aesthetics, have an influence on walking. Cervero et al. (2009) cited Handy et al. (2002) and Frumkin et al. (2004) to assert that the characteristics of the built environment, including permeability, footpaths, lighting, security, density, and mixed land use, can influence walking both as a transport mode and as an access mode to public transport. Evidence on the geographical location and attributes of the built environment on walking trips need to be qualified by the interdependence identified above by Iacono et al. (2008). Corpuz et al. (2005) identified differences in walking behavior by geographical location in Sydney: Residents of highly urbanized areas tended to walk more and the distribution between walking and car trips was associated with differences in the supply of public transport. In Bogota, Cervero et al. (2009) found that road facility designs like street density, connectivity, and proximity to ciclovia (cycleway) lanes were associated with physical activity, while other attributes of the built environment, like density and land-use mixtures, were not. However, Cervero et al. (2009) noted neighborhoods in Bogota are uniformly compact and mixed in their land use. In a rare study on egress trips from public transport, Townsend and Zacharias (2010) found the only variables to display significant correlation with walking distance from rail rapid transit stations in Bangkok were destination types, a proxy for both land use and activity.

Amenity and aesthetics are also potential influences on walking distance. But in assessing the impact of a range of factors, including aesthetics on choosing a route for walking, Agrawal et al. (2008) found that the primary consideration for commuters walking to five rail transit stations in the study in California and Oregon was minimizing the time and distance walked. Safety (from traffic, rather than crime) was a secondary factor in route choice, while environmental appearance, such as attractive landscaping or buildings, was less of a concern.

Natural environment elements, such as climate and topography, have been cited as factors that can influence walking, but the evidence is mixed. For walking as a mode, Burke et al. (2006) examined the influence of climate and topography on walking trip rates in Brisbane, Australia, and concluded that natural environmental conditions appeared to have little influence on the propensity of people to walk. Lee and Moudon (2006) found the physical environment contributed significantly in explaining the probability of walking in Seattle. Hills were negative for transportation walking, not recreational walking, possibly because transportation walking has more to do with reaching a certain place along the shortest route rather than the quality of the route, while recreational walking can be more flexible and people might choose certain routes based on route qualities (Lee and Moudon 2006).

Considering walking as an access mode to public transport, Walton and Sunseri (2010) examined public transport users in New Zealand cities Auckland and Wellington to understand factors influencing the decision to walk to public transport and concluded that impediments to walking found in research elsewhere almost all disappeared except chance of rain. In contrast, Wibowo and Olszewski (2005) found that the effort of walking to access MRT stations in Singapore was affected not only by walking distance but also by characteristics of the walking route, such as number of road crossings, ascending steps, and conflict points.

In relation to public transport supply, Burke and Brown (2007) found that in South East Queensland, Australia, where walking distance to bus stops was significantly shorter than to train stations or to ferry terminals, there were statistically significant differences in the variances of the walking distance distributions to bus stops and train stations and a greater proportion of travellers walking very short distances (less than 500 meters) to bus stops, which was attributed to the greater number and availability of bus stops compared to train stations. Similarly, Alshalalfah and Shalaby (2007) concluded that the density of the public transport route network in downtown Toronto, Canada, resulted in lower walking access distances than in other parts of the city.

A consistent finding of walking distance research, including Agrawal et al. (2008) in California and Oregon, Alshalalfah and Shalaby (2007) in Toronto, Canada, and Ker and Ginn (2003) to access rail in Perth, Australia, is that people walk considerably farther to access public transport than commonly assumed "rules of thumb." This finding has implications for both transport and land-use planning, including transit-oriented developments (Canepa 2007). People also walk farther than assumed for purposes other than access to public transport (Iacono et al. 2008; Larsen et al. 2010).

In summary, previous research suggests that walking distance to public transport may be influenced by the purpose of the overall trip, by demographic factors, particularly age and gender, and by the location of the access trip in terms of built environment and natural environment, although the impacts are variable. It is difficult to disentangle the effect of the built environment on walking access to public transport because of 
the interdependencies between access distances and supply of services. Overall, it appears that built and natural environment factors determine the ease of walking but the supply of public transport, including mode type, might be more of a factor in determining how far people walk to public transport once the decision to walk to public transport has been made.

\section{Data for Sydney}

Sydney has an extensive public transport network and travel data available from the Sydney Household Travel Survey. Sydney's rail network has 307 metropolitan stations including over 200 stations in Sydney and Central Coast and the rest in the adjoining regions of Hunter, Illawarra, and Southern Highlands, and the bus network has over 35,000 bus stops in the equivalent area. Over 10 percent of trips each weekday in Sydney are made by public transport, with a similar proportion of trips by train ( 5.2 percent) and by bus ( 5.8 percent), although train trips are longer and account for a higher proportion of total distance travelled (Transport Data Centre 2010). The Sydney Household Travel Survey (HTS) is a one-day travel diary covering the greater metropolitan area comprising the Sydney Statistical Division, Illawarra Statistical Division, and Newcastle Statistical Subdivision, running continuously since 1997-98 (Transport Data Centre 2010). The face-to-face interview survey for data collection ensures high data quality and maximizes response rates.

\subsection{Walking trips and walking distance}

Data from the last three years (2006-07, 2007-08 and 200809) of the HTS was used, due to changes in the estimation of walking distance since 1997 . For the three years of pooled data, 24,806 people were interviewed from 9561 households (66 percent household response rate), giving a total of 105,391 trip records (Transport Data Centre 2010). Due to very small mode shares for ferry, monorail, and light rail and the very uneven spatial distribution of these modes, the research focused on access from home to bus and train. In the three-year sample, there were a total of almost 2000 walk trips from home to access either a bus stop or train station.

The HTS records the street address of each household, which is then geocoded to $\mathrm{x}, \mathrm{y}$ coordinates. For the first trip away from home by public transport on the interview day, the interviewer asks for the location of the public transport stop. For walking trips to the train, the station named by the respondent is recorded by the interviewer and the $\mathrm{x}, \mathrm{y}$ coordinates are known. For walking trips to the bus, the respondent may identify the transit stop number or, more usually, describe the location of the bus stop in terms of streets, which are recorded by the interviewer. A hierarchy of geocoding methods is then used to identify the $\mathrm{x}, \mathrm{y}$ coordinates. For privacy and confidential- ity reasons, the exact home address and public transport stop location were not provided in the dataset, only the estimated walking distance from home to the train station or bus stop.

Calculation of walking distance from home to the public transport stop is a significant issue for this research. The current method of distance estimation in the HTS is based on each trip origin and destination being coded to an $\mathrm{x}, \mathrm{y}$ coordinate and road network distance calculated using ARCGIS. This is an approximation of the distance actually walked for several reasons. Walkers might not use the road network; instead they might walk through parks and open space or use pedestrianonly links, which reduce their walking distance. Alternatively, they might walk longer than the shortest road network distance, depending on the facilities for crossing roads, their ability, and their confidence. Walkers might also choose a longer route than the shortest road distance because the longer route is more attractive or avoids negative elements.

For the data used in this analysis, for bus users living within 100 meters of a bus stop, a walking distance of 50 meters has been imputed. For train trips, almost all walking trips are longer than 100 meters as the location of the train station is represented by the center of the station platform, which is usually 200 meters long. The dataset of 1952 trips included only a few very long walking trips from home with 97.6 percent of trips less than two kilometers and only three trips longer than five kilometers. For the purposes of further analysis, only trips less than two kilometers were included, reducing the dataset to 1906 trips. Figure 1 shows the frequency distribution for walking trips to public transport less than two kilometers.

\subsection{Explanatory variables}

A range of potential explanatory variables was collected as part of the HTS and these were provided for each walking trip. The dataset used is summarized in Table 2.

The location of the walking trip was considered in several ways for analysis. The location of the walking trip was known in terms of the local government area (LGA), which was the basis for defining other spatial variables. There are over 50 LGAs in greater Sydney that vary in spatial and population size. Each LGA was categorized as inner Sydney, outer Sydney, Sydney fringe, Central Coast, Newcastle, or Illawarra. Inner Sydney and outer Sydney are defined by the Department for Local Government, with inner Sydney including 21 LGAs in the inner ring around the Sydney central business district (CBD). Based on the LGA, each trip was also assigned to a bus contract region, with some LGAs split across more than one bus region. Other location variables included population density in each LGA from census data, and the proportion of all trips in each LGA made by public transport from the HTS. Correlations between the locational variables are discussed in the next section. 


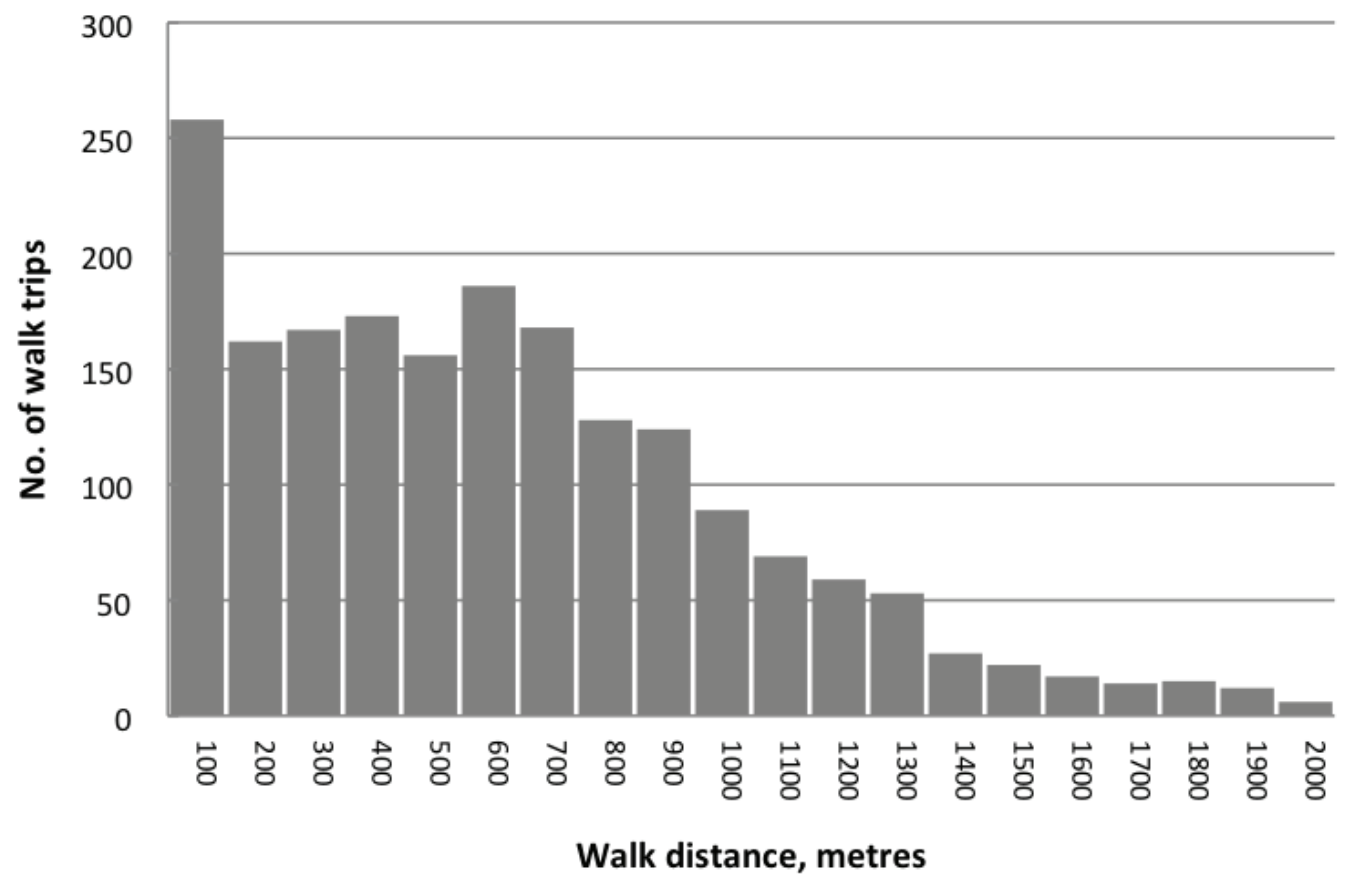

Figure 1: Frequency of walking distance from home to public transport for walking trips less than two kilometers ( $\mathrm{n}=1906)$.

Table 2: Potential explanatory variables from Sydney.

\begin{tabular}{|c|c|}
\hline Type of variable & Variables and categories \\
\hline $\begin{array}{l}\text { Trip characteristics-walking trip } \\
\text { from home }\end{array}$ & $\begin{array}{l}\text { - Distance of walking trip (calculated from origin and destination } \mathrm{x}, \mathrm{y} \text { coordinates, using ARCGIS road network } \\
\text { distance between these points) } \\
\text { - Destination of walking trip: train, bus (government or private bus), school bus } \\
\text { - Day of week of walking trip: weekday, weekend } \\
\text { - Time of day of walking trip: am peak, inter-peak, pm peak, evening } \\
\text { - Location of bus stop or train station: local government area }\end{array}$ \\
\hline $\begin{array}{l}\text { Trip characteristics—-public transport } \\
\text { trip after walking trip }\end{array}$ & $\begin{array}{l}\text { - Purpose of trip: work, education, social/recreational, shopping, personal business } \\
\text { - Duration of trip (minutes) } \\
\text { - Type of public transport: train, bus (government or private), school bus } \\
\text { - Fare type for trip: full fare, concession fare, free (school pass) } \\
\text { - Ticket type for trip: single, return, periodical, multi-trip ticket, etc. }\end{array}$ \\
\hline Demographic characteristics & $\begin{array}{l}\text { - Age: younger than } 19 \text { years, } 19-29 \text { years, } 30-49 \text { years, 50-64 years, } 65 \text { years and older } \\
\text { - Sex: male, female } \\
\text { - Personal income per year: which for analysis was grouped as less than } \$ 13,000, \$ 13,000-41,599, \$ 41,600- \\
83,199, \$ 83,200 \text { and over } \\
\text { - Labor force status: full-time work, part-time work, economically inactive, post-school education, school student } \\
\text { - Household size: number of persons } \\
\text { - Driver's license holding: yes, no } \\
\text { - Number of vehicles in household } \\
\text { - Physical disabilities restricting walking: yes, no }\end{array}$ \\
\hline Other & $\begin{array}{l}\text { - Reason for public transport use for work trip: avoids parking problems, cheaper, faster, do not have car, less } \\
\text { stressful than other forms, live or work close to public transport, don't drive/no license }\end{array}$ \\
\hline
\end{tabular}

As an indicator of public transport supply, the proportion of households in each bus contract region within 400 meters of a bus stop with a defined level of service was calculated by the Bureau of Transport Statistics using network and population data, although this does not fully measure the quality of the public transport (where the bus service goes, how long it takes to get there, or what activities the bus service provides access to). Figure 2 shows access to bus stops by bus contract region.

Other variables that might have been useful but were not available include the locational characteristics of the walking trip such as presence of a footpath, quality of the walking environment, the gradient of the walk trip, and the weather at the time and location of the walking trip. 


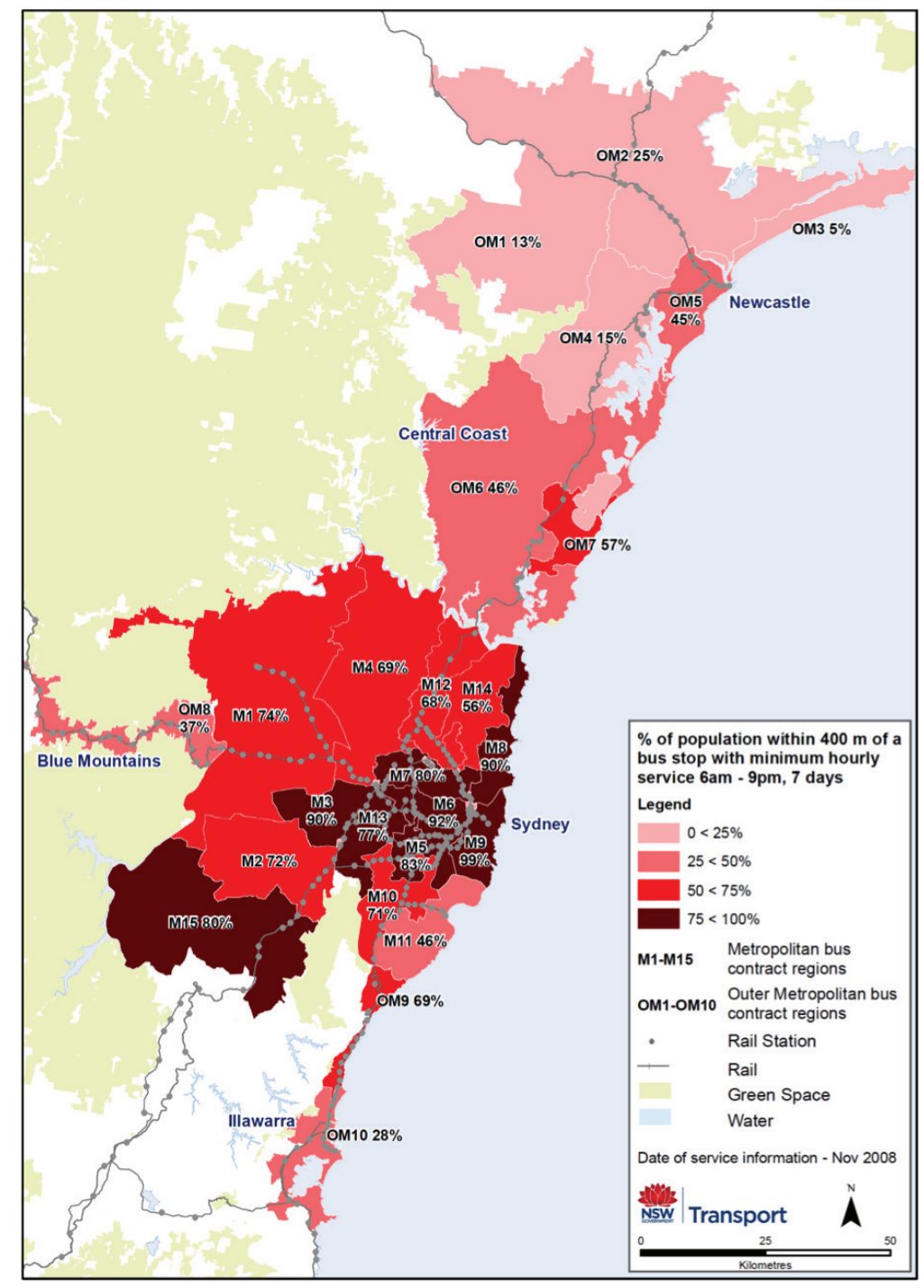

Figure 2: Access to bus services by bus contract region.

Source: Bureau of Transport Statistics (Metropolitan contract regions, data request 09/377; Outer metropolitan contract regions, data request no. 10/287).

\section{4}

\section{Influences on walking distance to public transport}

Analysis of influences on walking distance to public transport was conducted in three stages. First, walking distance was described in terms of its central tendency and shape. Second, the relationship between walking distance to public transport and possible explanatory variables was analyzed. Finally, the potential causal relationship between walking distance to public transport and the characteristics of the walking trip, the characteristics of the walker, and characteristics of public transport were investigated.

\subsection{Describing the distribution of walking distance}

\section{Mean walking distance}

Table 3 reports the mean walking distance and quartiles calculated for each explanatory variable described in Table 2. Overall average walking distance to public transport is 573 meters, with 25 percent of trips less than 235 meters and 75 percent of walking trips less than 824 meters. Table 3 also reports the comparison of mean walking distance for each category of explanatory variable where the mean walking distance was compared to a base chosen for each category of variables and a pvalue reported for a two-tailed t-test of statistical significance. 
Table 3: Walking distance from home to public transport (meters). ${ }^{1}$

\begin{tabular}{|c|c|c|c|c|c|c|c|c|}
\hline Variable & Category $^{2}$ & $\mathbf{N}$ & Mean $^{3}$ & p-value ${ }^{4}$ & $\mathrm{SD}^{5}$ & $\mathbf{L Q}^{5}$ & Median & $\mathrm{UQ}^{5}$ \\
\hline Total & - & 1906 & 573 & - & 417 & 235 & 518 & 824 \\
\hline \multicolumn{9}{|l|}{ Trip characteristics } \\
\hline \multirow[t]{3}{*}{ Transport mode } & Train & 667 & 805 & ${ }^{* *} \mathbf{0 . 0 0 0}$ & 375 & 539 & 749 & 1018 \\
\hline & Bus & 1084 & 461 & Base & 382 & 162 & 364 & 655 \\
\hline & School bus & 155 & 360 & ${ }^{* *} 0.002$ & 386 & 50 & 185 & 600 \\
\hline \multirow[t]{6}{*}{ Region } & Inner Sydney & 968 & 570 & Base & 385 & 273 & 520 & 785 \\
\hline & Outer Sydney & 638 & 636 & ${ }^{* *} 0.003$ & 452 & 261 & 572 & 922 \\
\hline & Sydney fringe & 46 & 446 & ${ }^{*} \mathbf{0 . 0 3 4}$ & 429 & 50 & 342 & 781 \\
\hline & Central Coast & 69 & 327 & ${ }^{* *} 0.000$ & 338 & 50 & 185 & 611 \\
\hline & Newcastle & 85 & 435 & ${ }^{* *} 0.002$ & 435 & 52 & 285 & 676 \\
\hline & Illawarra & 56 & 518 & 0.322 & 421 & 144 & 421 & 805 \\
\hline \multirow{4}{*}{ Trip purpose } & Work & 695 & 646 & Base & 418 & 316 & 582 & 900 \\
\hline & \begin{tabular}{|l|} 
Education \\
\end{tabular} & 471 & 483 & ${ }^{* *} 0.000$ & 412 & 97 & 400 & 778 \\
\hline & Shopping/pers business & 394 & 501 & ${ }^{* *} \mathbf{0 . 0 0 0}$ & 383 & 179 & 429 & 738 \\
\hline & Social/recreation & 295 & 639 & 0.817 & 429 & 304 & 582 & 878 \\
\hline \multirow[t]{4}{*}{ Fare type } & Full fare & 952 & 636 & Base & 419 & 312 & 580 & 889 \\
\hline & Free: school pass & 333 & 425 & ${ }^{* *} \mathbf{0 . 0 0 0}$ & 393 & 50 & 320 & 679 \\
\hline & Concession: pensioner & 251 & 485 & ${ }^{* *} \mathbf{0 . 0 0 0}$ & 372 & 202 & 403 & 685 \\
\hline & Concession: student & 189 & 643 & 0.832 & 411 & 318 & 582 & 921 \\
\hline \multirow[t]{3}{*}{ Ticket type } & Single or return & 636 & 632 & Base & 425 & 287 & 582 & 906 \\
\hline & Periodical pass & 569 & 645 & 0.599 & 425 & 313 & 581 & 886 \\
\hline & Multi-trip ticket & 257 & 454 & ${ }^{* *} 0.000$ & 322 & 206 & 394 & 654 \\
\hline \multirow[t]{2}{*}{ Day of week } & \begin{tabular}{|l|} 
Weekday \\
\end{tabular} & 1638 & 569 & Base & 417 & 227 & 513 & 824 \\
\hline & Weekend day $^{6}$ & 268 & 601 & 0.251 & 416 & 285 & 555 & 826 \\
\hline \multirow[t]{4}{*}{ Time of day } & Am peak & 1164 & 554 & Base & 410 & 208 & 508 & 812 \\
\hline & Inter-peak & 532 & 587 & 0.135 & 420 & 263 & 511 & 814 \\
\hline & Pm peak & 83 & 593 & 0.404 & 392 & 256 & 570 & 825 \\
\hline & Evening & 127 & 682 & ${ }^{* *} 0.003$ & 461 & 330 & 633 & 1008 \\
\hline \multirow[t]{4}{*}{ Public transport trip duration } & Up to 15 minutes & 782 & 545 & Base & 384 & 234 & 501 & 775 \\
\hline & $15-29$ minutes & 689 & 567 & 0.300 & 419 & 235 & 518 & 790 \\
\hline & $30-44$ minutes & 267 & 604 & 0.057 & 451 & 229 & 520 & 922 \\
\hline & 45 minutes and longer & 168 & 680 & ${ }^{* *} \mathbf{0 . 0 0 1}$ & 480 & 292 & 644 & 1012 \\
\hline \multicolumn{9}{|l|}{ Demographic characteristics } \\
\hline \multirow[t]{2}{*}{ Sex } & Female & 977 & 563 & Base & 421 & 223 & 505 & 813 \\
\hline & Male & 929 & 584 & 0.270 & 411 & 250 & 531 & 844 \\
\hline \multirow[t]{5}{*}{ Age } & Younger than 19 years & 498 & 505 & ${ }^{* *} \mathbf{0 . 0 0 0}$ & 423 & 117 & 425 & 779 \\
\hline & $19-29$ years & 445 & 634 & 0.587 & 416 & 303 & 570 & 889 \\
\hline & $30-49$ years & 528 & 619 & Base & 400 & 305 & 583 & 870 \\
\hline & $50-64$ years & 241 & 600 & 0.547 & 448 & 265 & 511 & 836 \\
\hline & 65 years and older & 194 & 452 & ${ }^{* *} 0.000$ & 352 & 181 & 383 & 664 \\
\hline \multirow[t]{5}{*}{ Labor force status } & Full-time work & 685 & 644 & Base & 422 & 313 & 586 & 889 \\
\hline & Part-time work & 194 & 627 & 0.632 & 404 & 316 & 548 & 903 \\
\hline & Economically inactive & 385 & 488 & **0.000 & 378 & 208 & 397 & 693 \\
\hline & Post-school education & 194 & 621 & 0.512 & 408 & 290 & 570 & 902 \\
\hline & School & 429 & 484 & ${ }^{* *} 0.000$ & 417 & 78 & 398 & 775 \\
\hline \multirow{4}{*}{ Personal income pa } & Less than $\$ 13,000$ & 545 & 579 & ${ }^{*} 0.023$ & 432 & 208 & 531 & 848 \\
\hline & $\$ 13,000-41,599$ & 522 & 574 & ${ }^{*} 0.012$ & 410 & 256 & 502 & 812 \\
\hline & $\$ 41,600-83,199$ & 367 & 644 & Base & 410 & 319 & 597 & 901 \\
\hline & $\$ 83,200$ and over & 187 & 619 & 0.479 & 398 & 313 & 581 & 850 \\
\hline \multirow[t]{3}{*}{ Vehicles in household } & 0 & 521 & 573 & 0.569 & 405 & 256 & 512 & 795 \\
\hline & 1 & 750 & 587 & Base & 421 & 255 & 528 & 839 \\
\hline & 2 or more & 632 & 559 & 0.226 & 421 & 196 & 507 & 839 \\
\hline \multirow[t]{2}{*}{ Driving license } & Yes & 1007 & 611 & Base & 414 & 287 & 568 & 864 \\
\hline & No & 614 & 573 & |0.077 & 420 & 233 & 515 & 818 \\
\hline
\end{tabular}

1. Total is all HTS walk trips from home to public transport of less than 2 kilometers in 2006, 2007, and 2008.

2. Categories with fewer than 40 respondents or undefined ("other") are excluded from this table.

3. Mean walking distance is compared to a chosen base for each variable using a standard two-tailed t-test.

4. ${ }^{*}$ Significant with $\mathrm{p}<0.05,{ }^{* *}$ significant with $\mathrm{p}<0.01$ (all tests are two-tailed tests).

5. SD=Standard deviation; $\mathrm{LQ}=$ Lower quartile threshold (25\%); UQ=Upper quartile threshold (75\%).

6. Weekends include public holidays. 
For many of the variables, there was a statistically significant difference in mean walking distance when comparing the base to other values of the explanatory variable.

Differences by trip characteristics included:

- Walking trips to the train are significantly longer than walking trips to the bus, while walking trips to school buses are significantly shorter than walking trips to the bus.

- Walking trips in Central Coast and Newcastle and Sydney fringe are significantly shorter than walking trips in inner Sydney, while walking trips in outer Sydney are significantly longer than walking trips in inner Sydney.

- Walking trips for education and shopping/personal business are significantly shorter than walking trips for work.

- Walking trips in the evening are significantly longer than trips in the am peak.

- Walking trips for public transport trips more than 45 minutes long are significantly longer than walking trips for public transport trips less than 15 minutes.

Differences by demographic characteristics included:

- Walking trips by the young (younger than 19 years) and elderly (65 years and older) are significantly shorter than trips by those 30-49 years old.

- Walking trips by the economically inactive and school students are significantly shorter than trips by fulltime workers.

- Walking trips using a school pass or pensioner concession ticket are significantly shorter than trips paying full fare.
These findings are generally consistent with known characteristics of public-transport use. The longer walking trips in the evening (after 6 p.m.) reflect the Sydney planning guidelines (NSW Ministry of Transport 2006), which set different access standards for daytime and evening, with an aim that 90 percent of households are within 400 meters of a train station or bus stop (with a certain level of service) in the daytime and within 800 meters of a train station or bus stop outside the peak and inter-peak daytime.

\section{Distribution of walking distance}

Figure 3 and Figure 4 demonstrate the large difference in average walking distance to the train compared to the bus and show that the distributions are skewed. Not only do walkers to the different modes have different means, but walking distances are also differently distributed for each mode as shown in Figure 3. The distribution of walking distance to the train is approximately normal, whereas the distribution of walking distance to the bus is almost triangular. The conclusion is that in relation to the walking distances in Sydney, train and bus users appear to be different populations both in terms of mean and distribution. This is explored further in the next section.

The distributions reflect both the nature of the supply and spacing of train stations and bus stops and the distribution of land uses around stations and stops. The few short walking trips of less than 200 meters to a train station reflect the distance estimation to the center of the platform and the nature of station catchments. While train stations do have residential development around them, the immediate catchment is more likely to be nonresidential with rail corridor uses, commuter parking,

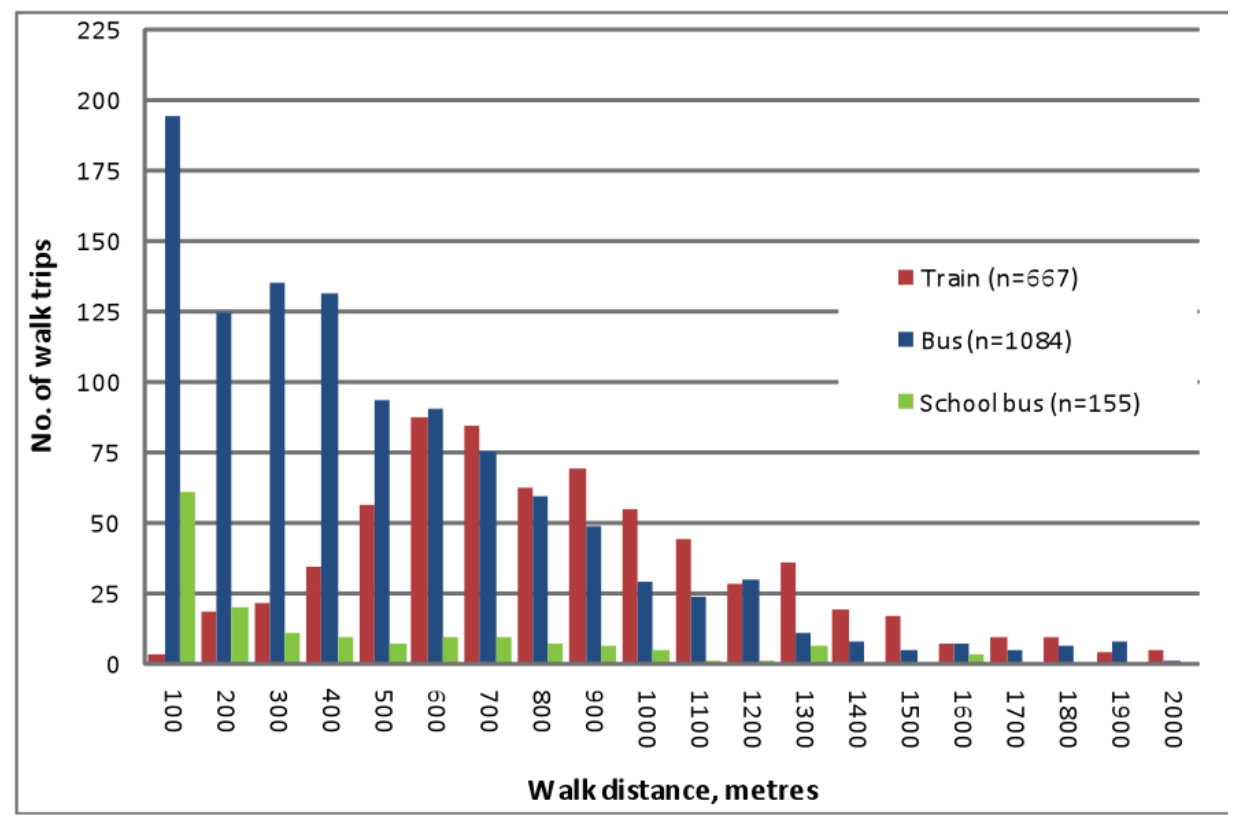

Figure 3: Distribution of walking distance by public transport mode. 


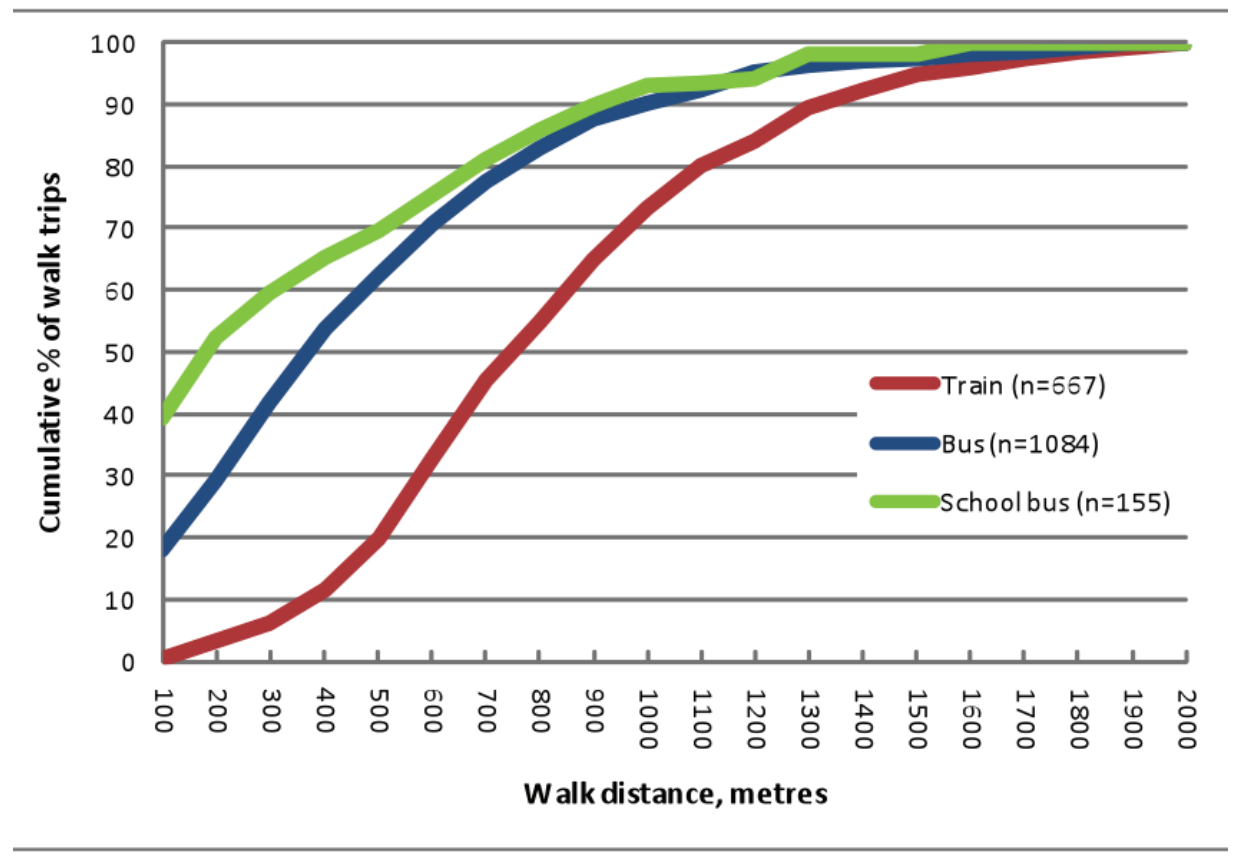

Figure 4: Cumulative frequencies for walking distance by public transport mode.

and commercial and retail uses. For instance, a 50-meter wide rail corridor containing tracks, embankments, maintenance access, signaling, and civil engineering structures occupies 15 percent of a 200-meter catchment around a station.

In contrast, a higher proportion of the 35,000 bus stops are in residential areas and are immediately surrounded by residential development, which reflects the planning guidelines' aim that 90 percent of people are within a 400-meter straightline distance of a station or bus stop (with a defined level of service) in daytime. Walking distance to school bus services has the most skewed distribution, reflecting that school bus services are provided where other scheduled bus services are not available or convenient and are planned based on the known home location of school students to minimize walking distance.

\subsection{Understanding differences between train and bus users}

Following the many significantly different means identified in Table 3 and to better understand differences between train and bus users, Chi-squared tests were used to identify whether there were statistically significant differences between train and bus users in terms of trip and demographic characteristics. School bus users were excluded from any further analysis because these trips have a unique set of related characteristics: All trips are undertaken by a specific age group (schoolchildren) for a

Table 4: Chi-squared tests of relationship between train and bus users (excluding school bus) and other variables.

\begin{tabular}{|l|r|l|l|}
\hline Variable & \multirow{2}{*}{$\chi^{2}$ sig. } & Relationship & Bus predominant \\
\cline { 3 - 5 } & & Train predominant \\
\hline Trip characteristicas & \multicolumn{3}{|l|}{} \\
\hline Trip purpose & 0.000 & Work & Education, shopping \\
\hline Weekday/weekend & 0.008 & Weekend & - \\
\hline Time of day & 0.002 & - & Inter-peak period \\
\hline Fare type & 0.000 & Full fare & Concession fare \\
\hline Ticket type & 0.000 & Periodical ticket & Multi-trip ticket \\
\hline Trip duration & 0.000 & Longer trips & Shorter trips \\
\hline Demographic characteristics & 0.000 & $19-49$ years & Younger than 19 years, \\
\hline Age & & & 65 years and older \\
\hline Sex & 0.013 & Men & Women \\
\hline Labor force status & 0.000 & Full-time work, post-school education & All others \\
\hline Personal income & 0.000 & - & Low income groups \\
\hline Cars in household & 0.112 & - & - \\
\hline Driving license & 0.000 & With license & Without license \\
\hline
\end{tabular}


Table 5: Walking distance from home to train (meters). ${ }^{1}$

\begin{tabular}{|c|c|c|c|c|c|c|c|c|}
\hline Variable & Category $^{2}$ & $\mathbf{N}$ & Mean $^{3}$ & p-value ${ }^{4}$ & $\mathrm{SD}^{4}$ & $\mathbf{L Q}^{4}$ & Median & $\mathrm{UQ}^{5}$ \\
\hline Total & Train & 667 & 805 & - & 375 & 539 & 749 & 1018 \\
\hline \multicolumn{9}{|l|}{ Trip characteristics } \\
\hline \multirow[t]{6}{*}{ Region } & Inner Sydney & 371 & 759 & Base & 360 & 512 & 688 & 963 \\
\hline & Outer Sydney & 259 & 873 & ${ }^{* *} \mathbf{0 . 0 0 0}$ & 386 & 590 & 829 & 1113 \\
\hline & Sydney fringe & \multicolumn{7}{|c|}{ Fewer than 20 trips } \\
\hline & Central Coast & \multicolumn{7}{|c|}{ Fewer than 20 trips } \\
\hline & Newcastle & \multicolumn{7}{|c|}{ Fewer than 20 trips } \\
\hline & Illawarra & \multicolumn{7}{|c|}{ Fewer than 20 trips } \\
\hline \multirow[t]{4}{*}{ Trip purpose } & Work & 341 & 810 & Base & 383 & 540 & 711 & 1037 \\
\hline & Education & 97 & 830 & 0.614 & 377 & 543 & 508 & 1050 \\
\hline & Shopping/per business & 102 & 754 & 0.156 & 337 & 519 & 745 & 930 \\
\hline & Social/recreation & 107 & 819 & 0.832 & 379 & 582 & 750 & 1038 \\
\hline \multirow[t]{4}{*}{ Fare type } & Full fare & 457 & 809 & Base & 380 & 534 & 748 & 1029 \\
\hline & Free: school pass & 40 & 725 & 0.176 & 315 & 503 & 671 & 913 \\
\hline & Concession: pensioner & 40 & 718 & 0.144 & 342 & 502 & 673 & 861 \\
\hline & Concession: student & 69 & 882 & 0.135 & 340 & 593 & 856 & 1130 \\
\hline \multirow[t]{3}{*}{ Ticket type } & Single or return & 278 & 815 & Base & 357 & 549 & 785 & 1034 \\
\hline & Periodical ticket & 287 & 810 & 0.872 & 392 & 541 & 721 & 1038 \\
\hline & Multi-trip ticket & \multicolumn{7}{|c|}{ Fewer than 20 trips } \\
\hline \multirow[t]{2}{*}{ Day of week } & Weekday & 546 & 805 & Base & 379 & 538 & 748 & 1017 \\
\hline & Weekend day & 121 & 804 & 0.995 & 357 & 541 & 748 & 1050 \\
\hline \multirow{4}{*}{ Time of day } & Am peak & 396 & 795 & Base & 371 & 538 & 727 & 997 \\
\hline & Inter-peak & 176 & 807 & 0.718 & 381 & 532 & 743 & 1080 \\
\hline & Pm peak & 30 & 772 & 0.744 & 359 & 543 & 749 & 943 \\
\hline & Evening & 65 & 873 & 0.118 & 389 & 607 & 804 & 1079 \\
\hline \multirow{4}{*}{$\begin{array}{l}\text { Public transport } \\
\text { trip duration }\end{array}$} & Up to 15 minutes & 258 & 759 & Base & 372 & 499 & 707 & 1008 \\
\hline & $15-29$ minutes & 211 & 801 & 0.221 & 363 & 546 & 737 & 963 \\
\hline & $30-44$ minutes & 108 & 891 & $* * 0.002$ & 389 & 581 & 848 & 1167 \\
\hline & 45 minutes or longer & 90 & 842 & 0.067 & 374 & 571 & 824 & 1085 \\
\hline \multicolumn{9}{|c|}{ Demographic characteristics } \\
\hline \multirow[t]{2}{*}{ Sex } & Female & 318 & 801 & Base & 381 & 526 & 748 & 1037 \\
\hline & Male & 349 & 808 & 0.810 & 369 & 551 & 748 & 1011 \\
\hline \multirow[t]{5}{*}{ Age } & Younger than 19 years & 99 & 854 & 0.250 & 388 & 577 & 791 & 1066 \\
\hline & $19-29$ years & 216 & 789 & 0.691 & 363 & 528 & 722 & 1005 \\
\hline & $30-49$ years & 241 & 803 & Base & 368 & 550 & 750 & 1036 \\
\hline & $50-64$ years & 86 & 814 & 0.806 & 417 & 512 & 758 & 1019 \\
\hline & 65 years and older & 25 & 727 & 0.328 & 327 & 564 & 716 & 836 \\
\hline \multirow[t]{5}{*}{ Labor force status } & Full-time work & 328 & 807 & Base & 383 & 538 & 743 & 1022 \\
\hline & Part-time work & 96 & 801 & 0.883 & 376 & 524 & 723 & 1045 \\
\hline & Economically inactive & 74 & 716 & 0.063 & 346 & 490 & 702 & 859 \\
\hline & Post-school education & 93 & 828 & 0.634 & 355 & 569 & 814 & 1048 \\
\hline & School & 69 & 846 & 0.442 & 367 & 582 & 785 & 1045 \\
\hline \multirow[t]{4}{*}{ Personal income pa } & Less than $\$ 13,000$ & 159 & 837 & 0.467 & 359 & 568 & 794 & 1051 \\
\hline & $\$ 13,000-41,599$ & 202 & 779 & 0.468 & 388 & 502 & 717 & 1011 \\
\hline & $\$ 41,600-83,199$ & 177 & 808 & Base & 383 & 539 & 761 & 1035 \\
\hline & $\$ 83,200$ and over & 80 & 815 & 0.893 & 361 & 574 & 698 & 959 \\
\hline \multirow[t]{3}{*}{ Vehicles in household } & 0 & 190 & 767 & 0.181 & 370 & 509 & 721 & 999 \\
\hline & 1 & 290 & 813 & Base & 366 & 552 & 745 & 1049 \\
\hline & 2 or more & 184 & 839 & 0.462 & 384 & 568 & 799 & 1020 \\
\hline Driving license & Yes & 424 & 799 & Base & 378 & 538 & 728 & 1009 \\
\hline & No & 194 & 824 & 0.440 & 370 & 549 & 763 & 1052 \\
\hline
\end{tabular}

1. Total is all HTS walk trips from home to train of less than 2 kilometers in 2006, 2007 and 2008.

2. Categories with fewer than 40 respondents or undefined ("other") are excluded from this table.

3. Mean walking distance is compared to a chosen base for each variable using a standard two-tailed t-test.

4. ${ }^{*}$ Significant with $\mathrm{p}<0.05,{ }^{* *}$ significant with $\mathrm{p}<0.01$ (all tests are two-tailed tests).

5. $\mathrm{SD}=$ Standard deviation; $\mathrm{LQ}=$ Lower quartile threshold (25\%); UQ = Upper quartile threshold (75\%).

6. Weekends include public holidays. 
Table 6: Walking distance from home to bus (excluding school bus) (meters). ${ }^{1}$

\begin{tabular}{|c|c|c|c|c|c|c|c|c|}
\hline Variable & Category $^{2}$ & $\mathbf{N}$ & Mean $^{3}$ & p-value ${ }^{4}$ & $\mathrm{SD}^{5}$ & $\mathrm{LQ}^{5}$ & Median & $\mathrm{UQ}^{5}$ \\
\hline \begin{tabular}{|l|} 
Total \\
\end{tabular} & Bus & 1084 & 461 & - & 382 & 162 & 364 & 655 \\
\hline \multicolumn{9}{|l|}{ Trip characteristics } \\
\hline \multirow[t]{6}{*}{ Region } & Inner Sydney & 586 & 454 & Base & 353 & 189 & 371 & 624 \\
\hline & Outer Sydney & 371 & 502 & 0.070 & 422 & 155 & 394 & 756 \\
\hline & Sydney fringe & \multicolumn{7}{|c|}{ Fewer than 20 trips } \\
\hline & Central Coast & 38 & 314 & $*^{*} 0.017$ & 310 & 50 & 167 & 541 \\
\hline & \begin{tabular}{|l|} 
Newcastle \\
\end{tabular} & 48 & 404 & 0.363 & 458 & 50 & 257 & 645 \\
\hline & Illawarra & 28 & 416 & 0.578 & 312 & 200 & 355 & 647 \\
\hline \multirow[t]{4}{*}{ Trip purpose } & Work & 354 & 488 & Base & 390 & 188 & 388 & 702 \\
\hline & Education & 224 & 414 & ${ }^{*} 0.023$ & 357 & 81 & 350 & 604 \\
\hline & Shopping/pers business & 289 & 414 & ${ }^{*} 0.014$ & 359 & 125 & 318 & 615 \\
\hline & Social/recreation & 186 & 537 & 0.174 & 424 & 240 & 411 & 757 \\
\hline \multirow[t]{4}{*}{ Fare type } & Full fare & 494 & 475 & Base & 387 & 167 & 372 & 676 \\
\hline & Free: school pass & 151 & 403 & $* 0.041$ & 372 & 50 & 322 & 624 \\
\hline & Concession: pensioner & 209 & 440 & 0.255 & 363 & 182 & 318 & 642 \\
\hline & Concession: student & 113 & 519 & 0.286 & 389 & 204 & 415 & 755 \\
\hline \multirow[t]{3}{*}{ Ticket type } & Single or return & 351 & 491 & Base & 421 & 159 & 392 & 699 \\
\hline & Periodical ticket & 278 & 480 & 0.726 & 391 & 194 & 370 & 664 \\
\hline & Multi-trip ticket & 253 & 448 & 0.150 & 321 & 202 & 366 & 641 \\
\hline \multirow[t]{2}{*}{ Day of week } & Weekday & 938 & 466 & Base & 381 & 165 & 371 & 660 \\
\hline & Weekend day ${ }^{6}$ & 146 & 430 & 0.298 & 386 & 125 & 330 & 607 \\
\hline \multirow{4}{*}{ Time of day } & Am peak & 616 & 447 & Base & 366 & 152 & 359 & 632 \\
\hline & Inter-peak & 353 & 477 & 0.242 & 397 & 183 & 370 & 681 \\
\hline & Pm peak & 53 & 491 & 0.406 & 376 & 191 & 479 & 758 \\
\hline & Evening & 62 & 480 & 0.508 & 448 & 158 & 353 & 620 \\
\hline \multirow{4}{*}{$\begin{array}{l}\text { Public transport trip dura- } \\
\text { tion }\end{array}$} & Up to 15 minutes & 467 & 442 & Base & 340 & 169 & 366 & 635 \\
\hline & $15-29$ minutes & 420 & 480 & 0.135 & 398 & 167 & 371 & 692 \\
\hline & $30-44$ minutes & 136 & 443 & 0.986 & 398 & 105 & 326 & 639 \\
\hline & 45 minutes and longer & 61 & 517 & 0.271 & 511 & 50 & 381 & 860 \\
\hline \multicolumn{9}{|l|}{\begin{tabular}{|l|} 
Demographic characteristics \\
\end{tabular}} \\
\hline \multirow[t]{2}{*}{ Sex } & Female & 583 & 462 & Base & 392 & 156 & 352 & 661 \\
\hline & Male & 501 & 459 & 0.892 & 370 & 171 & 374 & 639 \\
\hline \multirow[t]{5}{*}{ Age } & Younger than 19 years & 248 & 452 & 0.671 & 380 & 107 & 377 & 700 \\
\hline & $19-29$ years & 229 & 486 & 0.554 & 411 & 171 & 393 & 665 \\
\hline & $30-49$ years & 286 & 466 & Base & 359 & 189 & 376 & 655 \\
\hline & $50-64$ years & 154 & 482 & 0.674 & 421 & 188 & 343 & 656 \\
\hline & 65 years and older & 167 & 410 & 0.103 & 339 & 159 & 309 & 601 \\
\hline \multirow[t]{5}{*}{\begin{tabular}{|l|} 
Labor force status \\
\end{tabular}} & Full-time work & 357 & 492 & Base & 399 & 188 & 378 & 727 \\
\hline & Part-time work & 97 & 461 & 0.480 & 356 & 167 & 412 & 664 \\
\hline & Economically inactive & 308 & 434 & 0.052 & 367 & 171 & 318 & 631 \\
\hline & Post-school education & 101 & 429 & 0.154 & 358 & 150 & 344 & 617 \\
\hline & School & 209 & 453 & 0.254 & 387 & 93 & 382 & 699 \\
\hline \multirow[t]{4}{*}{ Personal income pa } & Less than $\$ 13,000$ & 332 & 481 & 0.777 & 412 & 156 & 381 & 683 \\
\hline & $\$ 13,000-41,599$ & 317 & 445 & 0.178 & 371 & 171 & 344 & 608 \\
\hline & $\$ 41,600-83,199$ & 190 & 491 & Base & 375 & 208 & 412 & 702 \\
\hline & $\$ 83,200$ and over & 107 & 471 & 0.651 & 359 & 187 & 332 & 721 \\
\hline \multirow[t]{3}{*}{\begin{tabular}{|l|} 
Vehicles in household \\
\end{tabular}} & 0 & 327 & 461 & 0.631 & 383 & 171 & 338 & 636 \\
\hline & 1 & 420 & 448 & Base & 388 & 156 & 343 & 615 \\
\hline & 2 or more & 337 & 477 & 0.301 & 372 & 159 & 407 & 736 \\
\hline \multirow[t]{2}{*}{ Driving license } & Yes & 554 & 479 & Base & 383 & 186 & 384 & 669 \\
\hline & No & 392 & 458 & 0.423 & 388 & 159 & 359 & 654 \\
\hline
\end{tabular}

1. Total is all HTS walking trips from home to bus (excluding school bus) of less than 2 kilometers in 2006, 2007, and 2008.

2. Categories with fewer than 40 respondents or undefined ("other") are excluded from this table.

3. Mean walking distance is compared to a chosen base for each variable using a standard two-tailed t-test.

4. ${ }^{*}$ Significant with $\mathrm{p}<0.05,{ }^{* *}$ significant with $\mathrm{p}<0.01$ (all tests are two-tailed tests).

5. $\mathrm{SD}=$ Standard deviation; $\mathrm{LQ}=$ Lower quartile threshold (25\%); UQ = Upper quartile threshold (75\%).

6. Weekends include public holidays. 
specific and compulsory purpose (education) in the am peak on weekdays. As all data are categorical, the Chi-squared $\left(\chi^{2}\right)$ significance reported in Table 4 relates to a contingency table between mode (bus or train) and the variable under consideration comparing the observed count with the expected count in each cell. Table 4 shows that train and bus users do vary in their trip and demographic characteristics, with statistically significant differences.

Differences by trip characteristics included:

- Train users are more likely to be traveling for work, and bus users for education or shopping.

- Train users are more likely to be traveling on weekends.

- Train users are more likely to be traveling on a full fare, and bus users on a concession fare.

- Train users are more likely to be making a longer trip by public transport, and bus users a shorter trip.

Differences by demographic characteristics included:

- Train users are more likely to be aged 19-49 years, and bus users younger than 19 years or 65 years and older.

- Train users are more likely to be male and bus users female.

- Train users are more likely to be in full-time work or tertiary education.

- Bus users are more likely to have low personal income.

- Train users are more likely to have a driving license and bus users less likely to have a license.

This pattern of relationships is internally consistent with train users having a set of characteristics associated with being employed and bus users with characteristics associated with not being employed. It is also consistent with other analyses on train and bus users using HTS data that highlights differences between the two groups (Transport Data Centre 2002: Transport and Population Data Centre 2003).

Given the differences between train and bus users shown in Table 4, Table 3 has been disaggregated for train and bus and presented separately in Table 5 and Table 6 . These tables show that very few of the significant differences in walking distance remain. The analysis of means, distributions, and Chi-squared analysis confirms that people walking to the bus and train are two different populations with respect to walking distance and their trip and demographic characteristics. This finding influences the approach to the regression models in the next section.

\subsection{Explaining walking distance}

Alternative location/geographical variables were included in regression models to identify if public transport supply (measured by the proportion of households in each of the bus contract regions within 400 meters of a bus stop with a defined level of service), population density at the LGA level and the proportion of all trips made by public transport in an LGA were significant factors in explaining walking distance, once the choice to walk had been made. As might be expected, there were strong correlations between these three variables (as shown in Table 7), suggesting multicollinearity would be an issue if all variables were included in the regression. As a result, only one of these variables was included at a time in the regression analysis reported below.

Table 7: Correlations between alternative locational variables in modeling.

\begin{tabular}{|l|l|l|}
\hline & \multicolumn{2}{|l|}{ Pearson Correlation coefficient } \\
\cline { 2 - 3 } & $\begin{array}{l}\text { \% of trips LGA using } \\
\text { public transport }\end{array}$ & $\begin{array}{l}\text { \% of population within } \\
\mathbf{4 0 0} \text { meters of bus stop }\end{array}$ \\
\hline $\begin{array}{l}\text { LGA population } \\
\text { density }\end{array}$ & $0.753^{* * *}(\mathrm{~N}=1751)$ & $0.658^{* * *}(\mathrm{~N}=1738)$ \\
\hline $\begin{array}{l}\text { \% of trips in } \\
\text { LGA using public } \\
\text { transport }\end{array}$ & - & $0.589^{* * *}(\mathrm{~N}=1738)$ \\
\hline
\end{tabular}

\section{Modeling distance to the train and bus combined}

Although the previous section (Section 4.2) identified the distribution of walking distance to the train is different from walking distance to bus, initial investigation to explain walking distance tested a regression model with a dummy variable to distinguish between train and bus users. This approach revealed two problems. First, the dominant feature was the explanation given by the mode dummy variable to the exclusion of any contribution from the wide variety of potential explanatory variables. Second, and more important, combining two different distributions, of which the walking distance to the bus distribution is highly non-normal, meant the residuals were significantly non-normal and thus any statistical tests of significance would be unreliable. Both these reasons indicated that separate regressions to explain walking distance to the train and walking distance to bus would be a better approach.

\section{Modeling distance to the train and bus separately}

Separate regressions to explain walking distance to the train and walking distance to the bus using demographic and trip characteristics and location/geographical variables were undertaken.

For walking distance to the train, a number of model formulations were investigated including spatial, trip, and demographic factors as potential explanatory variables. It was not possible to improve on a regression model with a single explanatory variable of the proportion of trips in an LGA by public transport, which had a very low $\mathrm{R} 2=0.008$. The interpretation is that the greater the proportion of trips made by public transport in an area, the shorter the walking distance to the train. 
In this case, proportion of trips by public transport is not an explanatory variable as such but more a measure of accessibility and public transport supply.

For walking distance to the bus, as with walking distance to the train, the distribution is heavily skewed as shown in Figure 3 , so walking distance was transformed to the square root of walking distance to ensure the regression residuals were normally distributed. A number of model formulations were investigated including spatial, trip, and demographic characteristics as potential explanatory variables for walking distance to the bus. All regressions displayed low adjusted R2 even though in many cases the $\mathrm{F}$ test confirmed that the adjusted R2 was significantly different from zero. The best fit was a model with a very low adjusted $R 2=0.02$.

In summary, the attempts to model the mode-specific data with the demographic and trip-related variables resulted in little extra explanation of walking distance variance. Indeed, the fact that the analysis was unable to find good independent variables to explain walking distance to the train and walking distance to the bus confirms that, once the decisions to take public transport and walk to public transport have been made, the choice of train or bus is the dominant factor, with demographic and trip-related variables not playing a significant role in explaining walking distance.

\section{$5 \quad$ Discussion and conclusions}

Analysis of the Sydney HTS data with almost 2000 walking trips showed that the main influence on walking distance from home to public transport, once people have made the decision to walk, was the mode of public transport walked to, whether train or bus. People walk farther from home to access a train than to access the bus. Average walking distance to public transport demonstrated significant differences in relation to demographic and trip-type variables, as shown in Table 3. But further analysis showed that use of bus or train mode itself is strongly associated with a number of trip-type and demographic variables.

But the contribution of this research is to move beyond a comparison of means. It shows that, once the choice of using public transport has been made, the only real explanation of walking distance is the mode of public transport used. Variability in walking distance largely reflects differences in the supply of each mode of public transport. Walking distances to train and bus reflect the different number and spacing of train stations and bus stops: People have to walk farther to reach one of the 300 train stations than to reach one of the 35,000 bus stops. In addition, train stations are more likely to be immediately surrounded by nonresidential land uses in their close catchment compared to bus stops.

Given the walking distances to the train, it is likely some people walk past a bus stop to access a train station, and choose to do so due to total access time and cost and the destinations served by the train compared to bus. Train trips are also usually longer than bus trips, in both distance and time. The Sydney HTS data do show that train trips are longer in distance (average 19 kilometers for train, 6.4 kilometers for bus) and longer in duration than bus trips (average 34 minutes for train, 23 minutes for bus) (TDC 2010). This suggests the train has more of a regional travel role, whereas the bus has more of a neighborhood role. While both train stations and bus stops allow users to access public transport, the modes are not necessarily interchangeable in the current Sydney network.

As well as differences in the number of train stations and bus stops, there are also differences in facilities between train stations and bus stops, with a higher level of facilities for users at train stations than at bus stops, which could influence users. In Sydney, train stations are usually staffed, have shelter, seating, lighting, printed and electronic timetable information, a public telephone, and help points. Very few if any bus stops have all of these characteristics. At a minimum, bus stops have a post with a sign. Some bus stops, but not all, have facilities such as timetables, seats, and shelter. The research focused on people who had already chosen to walk to access public transport, and thus it did not model choice of access mode to public transport. While 90 percent of bus users do walk to the bus stop, only half of train users walk to the train station from home.

The results support evidence from other research that people will walk farther than 400 meters to access public transport once they have decided to walk. However, equally important, it is not known how many more people would have used public transport or walked to the stop or station, if the stop or station was closer to home. The HTS includes two relevant questions that provide some information on this issue: reasons for mode choice for the work trip, and difficulty using any form of transport, including walking, because of a physical condition or disability. One in five (18 percent) public transport users say they travel to work by public transport because they live or work close to public transport, and 12 percent of car commuters say they travel to work by car because public transport is unavailable here (Transport Data Centre 2010). In terms of difficulty using any form of transport including walking because of a physical condition or disability, only 3.3 percent of respondents in the dataset of walking to public transport trips had a condition restricting walking, which is similar to all respondents in the HTS (3.7 percent) (Bureau of Transport Statistics 2010).

The research also highlights well-known difficulties in measuring pedestrian accessibility to public transport, particularly inaccuracies associated with using radial catchments of population within 400 meters of a stop or station. Not all households in the 400-meter catchment will actually have a walk of less than 400 meters: The actual walking distance to the 
stop can be substantially longer for many households, depending on the road network and topographical barriers. It is more difficult to incorporate these factors into measures using available data sources, even though the importance is well-recognized. Iacono et al. (2010) noted that difficulties in calculating non-motorized accessibility measures include data quality, zonal structure of transport planning models, and the adequacy of models and travel networks for describing and predicting travel by non-motorized modes. However, recently Foda and Osman (2010) have developed ideal and actual stop-accessibility indices to measure the accessibility of a bus stop considering the actual pedestrian road network and a stop coverage ratio index, while Alam et al. (2010) showed that an alternative method for calculating accessibility indices, using a gravity-based measure of accessibility, is more accurate than traditional measures of the proportion of travel zones with a quarter-mile buffer of public transport.

It is an important result that, for those who have chosen public transport as a means of travel, walking distance is not affected by significant demographic characteristics such as age. It suggests that the most important feature of walking distance is the availability of stops and stations. But increasing the number of stops and stations to reduce access distance is expensive and transport subsidy budgets are usually more or less fixed. Innovative ways of expanding access to public transport such as providing flexible transport services as an access mode to more distant public transport services, as discussed by Daniels and Mulley (2010b), might increase the mode share of public transport.

Perhaps more important, closing the spatial element of the accessibility gap for conventional public transport is often argued to be more important in areas with a larger older population or higher non-car ownership. But these demographic factors do not appear to influence differences in walking distance once people have decided to walk to public transport. To ensure equity in accessibility, it might be more important to ensure good access to public transport for all, regardless of the demographic characteristics of an area. The differences between train and bus users also suggest that accessibility initiatives for public transport might not be the same for each mode.

To better understand influences on walking distance to public transport and identify implications for service planning guidelines, future research requires more detailed information on the characteristics of the built and natural environment of the walking trip and on the attitudes of walkers such as whether they value the walking distance as a contribution to meeting their daily health requirements for physical activity. Further research areas include the maximum distances people are prepared to walk and whether people walk farther to more frequent services. Data from household travel surveys is the main source of data for walking distance research. But alternative methods such as pedestrians drawing their actual walking route on a map, as used by Agrawal et al. (2008), or tracking routes with on-person GPS devices as used in some travel surveys, would assist research by measuring distance more accurately and identifying the characteristics of the walking route.

\section{References}

Agrawal, A., M. Schlossberg, and K. Irvin. 2008. How far, by which route and why? A spatial analysis of pedestrian preference. Journal of Urban Design, 13 (1): 81-98. DOI: 10.1080/13574800701804074.

Alam, B., G. Thompson, and J. Brown. 2010. Estimating transit accessibility with an alternative method: evidence from Broward County, Florida. Transportation Research Record, 2144: 6271. DOI: 10.3141/2144-08.

Alshalalfah, B. and A. Shalaby. 2007. Case Study: Relationship of walk access distance to transit with service, travel and personal characteristics. Journal of Urban Planning and Development, 133 (2): 114-118. DOI: 10.1061/ (ASCE)0733-9488(2007)133:2(114).

Besser, L. M. and A. Dannenberg. 2005. Walking to public transit: steps to help meet physical activity recommendations. American Journal of Preventive Medicine, 29 (4): 273280. DOI: 10.1016/j.amepre.2005.06.010.

Bureau of Transport Statistics. 2010. Physical restrictions by mode. Data request no. 10/472.

Burke, M. and A. Brown. 2007. Distances people walk for transport. Road and Transport Research, 16 (3): 16-29.

Burke, M., N. Sipe, R. Evans, and D. Mellifont. 2006. Climate, geography and the propensity to walk: environmental factors and walking trip rates in Brisbane. Papers of the 29th Australasian Transport Research Forum, Gold Coast, September 27-29, 2006. www.patrec.org/atrf.aspx (Accessed February 11, 2011).

Canepa, B. 2007. Bursting the bubble: determining transitoriented development's walkable limits. Transportation Research Record, 1992: 28-34. DOI: 10.3141/1992-04.

Cervero, R., O. Sarmiento, E. Jacoby, L. Gomez, and A. Neiman. 2009. Influences of Built Environments on Walking and Cycling: Lessons from Bogotá. International Journal of Sustainable Transportation, 3(4): 203-226. DOI: 10.1080/15568310802178314.

Corpuz, G., A. Hay, and D. Merom. 2005. Walking for transport and health: trends in Sydney in the last decade. Papers of the 28th Australasian Transport Research Forum, Sydney, September 28-30, 2005. www.patrec.org/atrf.aspx (Accessed February 11, 2011).

Currie, G., J. Stanley, and J. Stanley, eds. 2007. No way to go: Transport and social disadvantage in Australian communities. 
Melbourne: Monash University ePress.

Daniels, R. and C. Mulley. 2010a. A proposal for accessibility planning in NSW: research and policy issues. Proceedings of the 33rd Australasian Transport Research Forum, Canberra, September 29-October 1, 2010. www.patrec.org/atrf.aspx (Accessed February 11, 2011).

Daniels, R. and C. Mulley. 2010b. Overcoming barriers to implementing flexible transport services in NSW. Proceedings of the 33rd Australasian Transport Research Forum, Canberra, September 29-October 1, 2010. www.patrec.org/ atrf.aspx (Accessed February 11, 2011).

Ewing, R. and R. Cervero. 2010. Travel and the built environment: a meta-analysis. Journal of the American Planning Association, 76(3): 265-294. DOI: 10.3141/1780-10.

Foda, M. and A. Osman. 2010. Using GIS for measuring transit stop accessibility considering actual pedestrian road network. Journal of Public Transportation, 13(4): 23-40.

Greater Vancouver Transportation Authority. 2004. Transit Service Guidelines Public Summary Report, Greater Vancouver Transportation Authority, Vancouver, Canada.

HKL. 2008. Public transport planning guidelines in Helsinki. HKL publication series A: 1/2008. Helsinki: HKL Planning Unit.

Iacono, M., K. Krizek, and A. El-Geneidy. 2008. Access to destinations: How close is close enough? Estimating accurate distance decay functions for multiple modes and different purposes. Report \#4 in the series: Access to Destinations Study. Hubert H. Humphrey Institute of Public Affairs University of Minnesota, Minneapolis. http://www.lrrb. org/PDF/200811.pdf (Accessed February 11, 2011.

Iacono, M., K. Krizek, and A. El-Geneidy. 2010. Measuring non-motorized accessibility: Issues, alternatives and execution. Journal of Transport Geography, 18: 133-140. DOI: 10.1016/j.jtrangeo.2009.02.002.

Ker, I. and S. Ginn. 2003. Myths and realities in walkable catchments: the case of walking and transit. Road and Transport Research, 12(2): 69-80.

Larsen, J., A. El-Geneidy, and F. Yasmin. 2010. Beyond the quarter mile: re-examining travel distances by active transportation. Canadian Journal of Urban Research: Canadian Planning and Policy (supplement), 19(10): 70-88.

Lee, C. and A. V. Moudon. 2006. Correlates of walking for transportation or recreation purposes. Journal of Physical Activity and Health 3, Suppl 1: S77-S98.

Lucas, K. 2005. Providing transport for social inclusion within a framework for environmental justice in the UK. Papers of 28th Australasian Transport Research Forum, Sydney. http://www.patrec.org/web_docs/atrf/papers/2005/ Lucas\%20(2005).pdf (Accessed February 11, 2011). DOI: 10.1016/j.tra.2005.12.005.

Lucas, K. 2010. Transport and social exclusion: Where are we now? Paper presented to the 12th World Conference on
Transport Research, July 11-15, Lisbon, Portugal. DOI: 10.1016/j.tranpol.2012.01.013.

Merom, D., H. van der Ploeg, G. Corpuz, and A. Bauman. 2010. Public health perspectives on household travel surveys: Active travel between 1997-2007. American Journal of Preventive Medicine, 39(2): 113-121. DOI: 10.1016/j. amepre.2010.04.007.

Neilson, G. and W. Fowler. 1972. Relation between transit ridership and walking distances in a low density Florida retirement area. Highway Research Record, 403: 26-34.

NSW Government. 2005. Metropolitan strategy city of cities: A plan for Sydney's future, December 2005. www.metrostrategy.nsw.gov.au (Accessed February 11, 2011).

NSW Government. 2010a. Metropolitan transport plan: Connecting the city of cities, February 2010. http://www.nsw. gov.au/metropolitantransportplan (Accessed February 11, 2011).

NSW Government. 2010b. NSW state plan 2010. http://more. nsw.gov.au/sites/default/files/pdfs/stateplan/09NSW_ State_Plan_Final.pdf (Accessed February 11, 2011).

NSW Government. 2010c. Metropolitan plan for Sydney 2036, December 2010. http://www.metroplansydney.nsw. gov.au/Home/MetropolitanPlanForSydney2036.aspx (Accessed February 11, 2011).

NSW Ministry of Transport. 2006. Service planning guidelines for Sydney contract regions. NSW Ministry of Transport, Sydney, Australia. http://www.transport.nsw.gov.au/ sites/default/file/busreform/service-planning-guidelines. pdf (Accessed February 11, 2011).

Public Transport Authority. 2003. Design and planning guidelines for public transport infrastructure: Bus route planning and transit streets. Public Transport Authority, Western Australia.

Townsend, C. and J. Zacharias. 2010. Built environment and pedestrian behavior at rail rapid transit stations in Bangkok. Transportation, 27: 317-330. DOI: 10.1007/s11116-0099226-8.

Transport Data Centre. 2002. Bus users in Sydney. Issues paper 2002/02, December 2002. www.bts.nsw.gov.au/ArticleDocuments/80/bus-users-2002.pdf.aspx (Accessed February 11, 2011).

Transport Data Centre. 2010. 2008/09 Household travel survey summary report. Transport Data Centre, Sydney, Australia. http://www.bts.nsw.gov.au/ArticleDocuments/79/2008_09_HTS_Summary_Report.pdf (Accessed February 11, 2011).

Transport and Population Data Centre. 2006. TransFigures: Train access and egress modes. www.bts.nsw.gov.au/ArticleDocuments/80/transfigures-nov06.pdf.aspx (Accessed February 11, 2011).

Transport and Population Data Centre. 2003. Train users in Sydney, November 2003. www.bts.nsw.gov.au/ 
ArticleDocuments/80/train-users-2003.pdf.aspx (Accessed February 11, 2011).

Walton, D. and S. Sunseri. 2010. Factors influencing the decision to drive or walk short distances to public transport facilities. International Journal of Sustainable Transportation, 4(4): 212-226. DOI: 10.1080/15568310902927040

Wibowo, S. S. and P. Olszewski, P. 2005. Modeling walking accessibility to public transport terminals. Case study of Singapore mass rapid transit. Journal of the Eastern Asia Society for Transportation Studies, 6: 147-156. 